\title{
Supramolecular analytical chemistry: spectrofluorimetric determination of 6-hydroxymelatonin with hydroxypropyl- $\beta$-cyclodextrin
}

\author{
A. Guillermo Bracamonte, Guadalupe G. Miñambres, and Alicia V. Veglia* \\ Instituto de Investigaciones en Físico Química de Córdoba (INFIQC), Departamento de \\ Química Orgánica, Facultad de Ciencias Químicas, Universidad Nacional de Córdoba. \\ Ciudad Universitaria, 5000 Córdoba, Argentina \\ E-mail: aveglia@fcq.unc.edu.ar
}

Dedicated to Prof. Emeritus Dr. Rita Hoyos de Rossi

\begin{abstract}
The effect of the addition of native $(\alpha, \beta$ and $\gamma$ ) and derivative (methyl- $\beta$ and hydroxypropyl- $\beta$ ) cyclodextrins (CD) on the fluorescence of 6-hydroxymelatonin $(6 \mathrm{HM})$ in water solutions was studied. The fluorescence of the substrate in the presence of hydroxypropyl- $\beta$-CD (HPCD) showed the maximum enhancement and the association constant $\left(\mathrm{K}_{\mathrm{A}}, \mathrm{mol}^{-1} \mathrm{~L}\right)$ was determined $(60 \pm 2)$ and interpreted. The fluorescence quantum yield ratio between the complex and free substrate $\left(\phi_{6 \mathrm{HMCD}} / \phi_{6 \mathrm{HM}}\right)=6.0 \pm 0.2$ provides analytical advantages. On the basis of this supramolecular interaction, an alternative and sensitive spectrofluorimetric method for the determination of $6 \mathrm{HM}$ was developed with a detection limit of $0.71 \mathrm{ng} \mathrm{mL} \mathrm{m}^{-1}$. The validation of the method was performed in urine samples with very good recoveries 95-109\%.
\end{abstract}

Keywords: Supramolecular interaction, 6-hydroxymelatonin, cyclodextrin, spectrofluorimetry, determination

\section{Introduction}

In the human organism, certain aromatic nuclei have important biological functions as hormones and neurotransmitters. Among them, the indoleamines are involved in numerous physiological processes. ${ }^{1}$ The $N$-acetyl-5-methoxytryptamine known as melatonin (M) is a naturally occurring compound found in animals, plants, and microbes. In mammals, $M$ is secreted into the blood by the pineal gland in the brain. Known as the "hormone of darkness", it is secreted in the darkness in both day-active (diurnal) and night-active (nocturnal) animals. It is involved in the physiology of circadian rhythms, in mammalian reproduction, it nowadays is 
used as a sleep disorder controller, and its antioxidant properties have been discussed in many studies. ${ }^{2}$ The metabolisation of melatonin produces 6-hydroxymelatonin $1(6 \mathrm{HM})$ that is excreted in urine. ${ }^{3}$ It has been reported that the diminished nocturnal excretion of $6 \mathrm{HM}$ is related to a lower M plasma concentration than that of normal levels. ${ }^{4}$

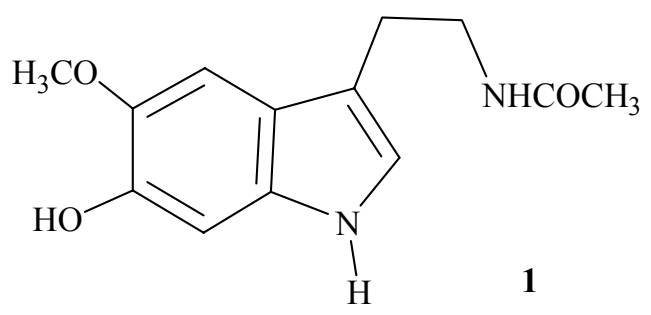

Several analytical methods have been described for the determination of $\mathrm{M}$ and $6 \mathrm{HM}$ in different biological matrices: radioimmunoassay (RIA), ${ }^{5}{\mathrm{GC}-\mathrm{MS}^{6} \text { and HPLC-MS }}^{7}$ achieve good detection limits but require costly equipments. Other less expensive methods with simple application have been reported involving derivatization reactions with fluorescence ${ }^{8}$ or chemiluminescence ${ }^{9}$ detection.

The biological importance of $\mathrm{M}$, as consequently of its metabolite in urine (6HM), and its low levels found in real matrices, offers a challenge of developing a sensitive, simple and alternative method for the determination of $6 \mathrm{HM}$. Supramolecular analytical chemistry ${ }^{10}$ could fulfill these requirements. In this area we have studied several aspects of the chemistry and applications of cyclodextrins (CD), ${ }^{11-14}$ which are cyclic oligosaccharides consisting of six $(\alpha \mathrm{CD})$, seven $(\beta \mathrm{CD})$ or eight $(\gamma \mathrm{CD})$ units of $\alpha-\mathrm{D}$-glucose linked by $\alpha-(1,4)$ bonds. Among the derivatives of native $\mathrm{CDs}$, methyl $\beta-\mathrm{CD}$ (mCD) and hydroxypropyl- $\beta$-CD (HPCD, 2hydroxypropyl- $\beta-\mathrm{CD}$ was employed) have higher solubility in water than $\beta C D$ and some analytical advantages, including binding affinities and selectivity. ${ }^{15}$ These macrocycles have a nanocavity $(0.7 \mathrm{~nm}$ internal diameter $\beta \mathrm{CD})$ which allows them to act as hosts and to form inclusion complexes with guest molecules in the solid state or in solution. ${ }^{16}$ The complex formation produces, in many cases, changes in the physical and chemical properties of the substrates included. ${ }^{15,16}$

Therefore, the aim of this work is to determine the best conditions for the direct spectrofluorimetric determination of $6 \mathrm{HM}$ and the effect of cyclodextrins as receptors, and to develop and validate a supramolecular spectrofluorimetric method in real samples, simplifying the experimental requirements and avoiding derivatization reactions.

\section{Results and Discussion}

\section{Effect of pH and cyclodextrins}

$\mathrm{UV} / \mathrm{Vis}$ spectra of $6 \mathrm{HM}$ in water solutions were taken at $\mathrm{pH} 2.00,6.994$ and 13.00 being practically the same from 2.00 to 6.994 with a wavelength of maximum absorption at $300.0 \mathrm{~nm}$ 
and a molar absorptivity of $(57.3 \pm 0.5) 10^{2} \mathrm{~cm}^{-1} \mathrm{~mol}^{-1} \mathrm{~L}$, but with a bathochromic shift to 315.0 $\mathrm{nm}$ and a 13-time increase in absorbance at this wavelength at $\mathrm{pH} 13.00$. This was interpreted as the phenol deprotonation. Therefore, a titration curve of absorbance as a function of the $\mathrm{pH}$ allowed determining the $\mathrm{pK}_{\mathrm{a}}$ value of $(10.24 \pm 0.01)$ (Figure 1). This value is similar to the value obtained for other substituted phenols ${ }^{17}$ but more acid than those obtained by us for 5hydroxyindoles (5-hydroxytryptamine and 5-hydroxy-3-indolylacetic acid, average value $11.14 \pm 0.04)^{18}$ indicating the dependence of the acid characteristic of hydroxyl group with the substituent position on the indole nucleus.

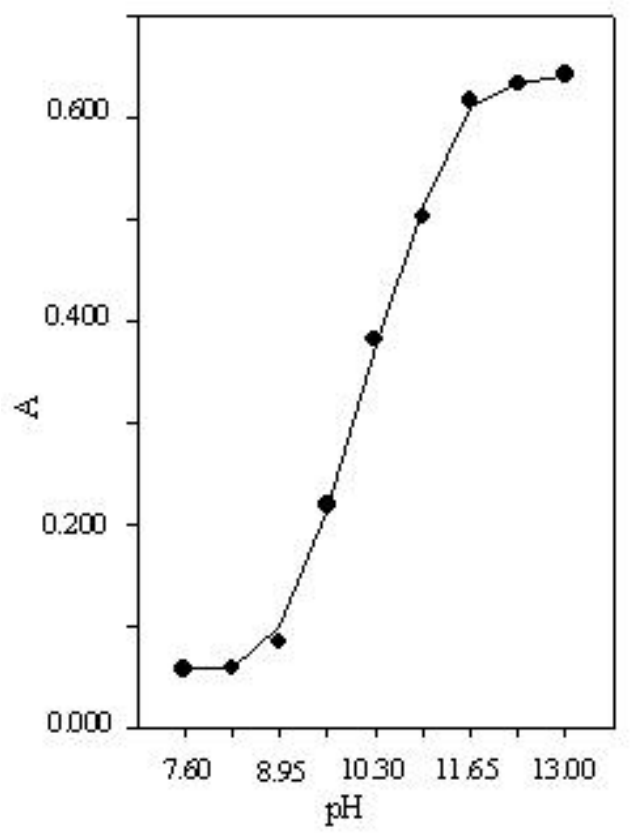

Figure 1. Absorbance of $6 \mathrm{HM} 1$ as function of $\mathrm{pH}$ at $319.0 \mathrm{~nm}$ and $25.0^{\circ} \mathrm{C}$

The fluorescence behaviour for 6HM at pH 6.994 with an emission wavelength $\left(\lambda^{\max }\right) 382.0$ $\mathrm{nm}$ showed a decrease in intensity and a shift in $\lambda_{\max }$ at $\mathrm{pH} 2.00(25 \%$ and $378.5 \mathrm{~nm})$ and 13.00 $(10 \%$ and $410 \mathrm{~nm})$. These effects were interpreted as deriving from the acidic and basic fluorescence quenching of the indole nucleus. ${ }^{13}$

The effect of $\alpha \mathrm{CD}, \beta \mathrm{CD}, \gamma \mathrm{CD}, \mathrm{mCD}$ and HPCD on the UV/VIS and fluorescence spectra of 6HM was observed at $\mathrm{pH} 2.00,6.994$ and 13.00 . In all cases, only small changes $(0.5-1.0 \mathrm{~nm})$ in the wavelength of maximum absorption were observed with no variation in absorption. The fluorescence $(F)$ was unaltered in the presence of $\alpha$ and $\gamma \mathrm{CD}$ at all the $\mathrm{pH}$ studied, but at $\mathrm{pH} 2.00$ and 6.994 important increases of $F\left(\Delta F=F^{C D}-F\right)$ were found in the presence of $10 \mathrm{mM}$ of $\beta \mathrm{CD}$ ( 22 and $42 \%$ ), $\mathrm{mCD}(30$ and $60 \%$ ) and HPCD (186 and $210 \%$ ), compared with those in buffer solution at the same $\mathrm{pH}$. Blue shifts in the $\lambda^{\max }(\mathrm{nm})$ were also observed at these $\mathrm{pH}$ (2.00 and 6.994) with $\beta C D$ ( 22 and 11$), \mathrm{mCD}$ ( 25 and 30$)$ and HPCD (35.5 and 39.5). Such changes in fluorescence and in $\lambda^{\max }$ correlate with an environment more hydrophobic than water. ${ }^{16}$ Furthermore, this behaviour was not exhibited in the presence of glucose (weight equivalent to 
$\left.10 \mathrm{mmol} \mathrm{L} \mathrm{L}^{-1} \beta \mathrm{CD}\right)$; this confirms that there is some specific interaction with $\beta \mathrm{CD}, \mathrm{mCD}$ and HPCD and suggests inclusion complex formation ${ }^{16}$ with these CD (Equation 1) as observed with other indole derivatives. ${ }^{12,18}$

$$
6 \mathrm{HM}+\mathrm{CD} \stackrel{\mathrm{K}_{\mathrm{A}}}{\rightleftharpoons} 6 \mathrm{HM}: \mathrm{CD}
$$

Taking into account the experimental results described above, we selected $\mathrm{pH} 6.994$ for all the determinations, since at this $\mathrm{pH}$ the fluorescence is high and a good $\mathrm{pH}$ for the treatment of biological samples. The association constants for one-to-one $(1: 1)$ stoichiometry $\left(\mathrm{K}_{\mathrm{A}}\right)$ and the fluorescent quantum yield ratios between free and complex substrate $\left(\phi_{6 \mathrm{HMCD}} / \phi_{6 \mathrm{HM}}\right)$ can be fitted from non-linear analysis of $F$ at different receptor concentrations (Equation 2) for $\mathrm{mCD}$ and HPCD (Table 1) (Figure 2 being representative).

$$
F / F_{0}=\left\{1+\left(\phi_{6 \mathrm{HMCD}} / \phi_{6 \mathrm{HM}}\right) \mathrm{K}_{\mathrm{A}}[\mathrm{CD}]\right\} /\left\{1+\mathrm{K}_{\mathrm{A}}[\mathrm{CD}]\right\}
$$

Table 1. Values of $\mathrm{K}_{\mathrm{A}}$ and $\left(\phi_{6 \mathrm{HMCD}} / \phi_{6 \mathrm{HM}}\right)$ determined for $6 \mathrm{HM}^{\mathrm{a}}$

\begin{tabular}{ccc}
\hline $6 \mathrm{HM}: \mathrm{CD}$ & $\mathrm{K}_{\mathrm{A}}{ }^{\mathrm{a}}\left(10 \mathrm{~mol}^{-1} \mathrm{~L}\right)$ & $\left(\phi_{6 \mathrm{HMCD}} / \phi_{6 \mathrm{HM}}\right)$ \\
\hline $6 \mathrm{HM}: \mathrm{mCD}$ & $12 \pm 2$ & $2.1 \pm 0.1$ \\
$6 \mathrm{HM}: \mathrm{HPCD}$ & $6.0 \pm 0.2$ & $6.0 \pm 0.2$ \\
\hline
\end{tabular}

${ }^{\mathrm{a}}$ At $\mathrm{pH}=6.994, \mu=0.124 \mathrm{~mol} \mathrm{~L}^{-1}$ and $25.0^{\circ} \mathrm{C}$.

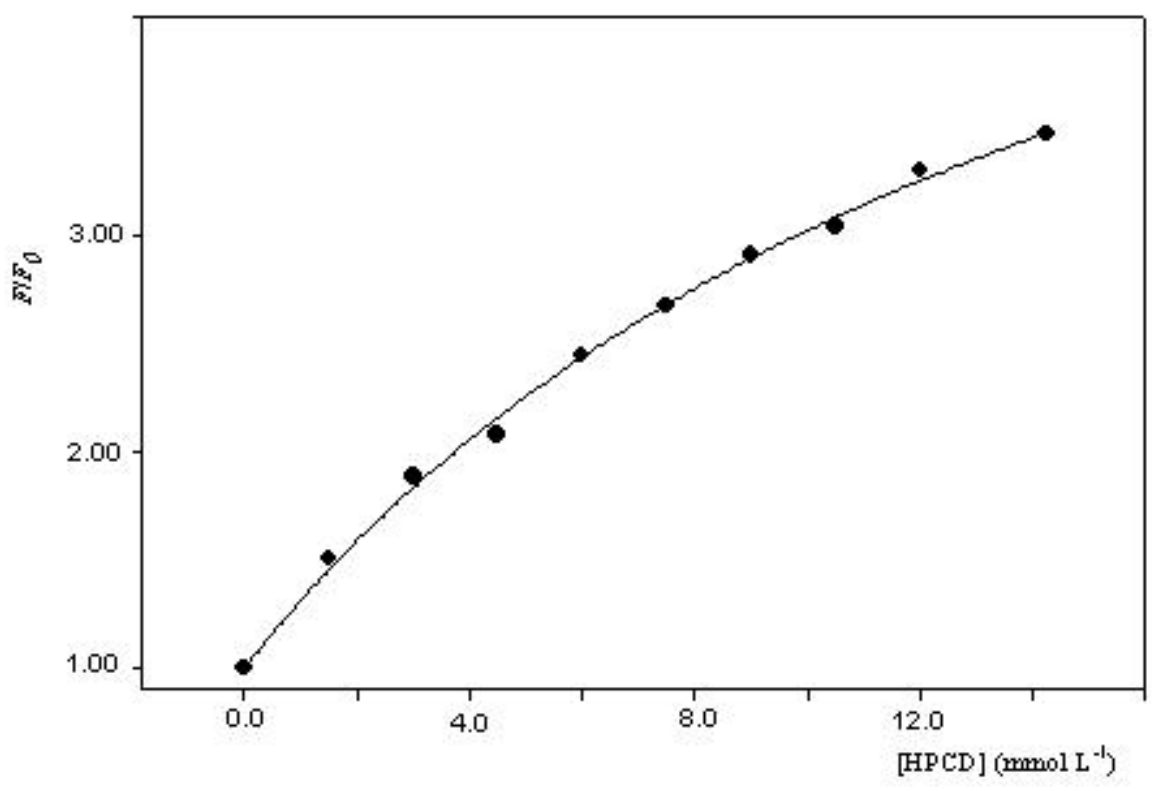

Figure 2. Relative fluorescence of $2.4 \mu \mathrm{mol} \mathrm{\textrm {L } ^ { - 1 }}$ solution of $6 \mathrm{HM}$ as a function of HPCD concentrations at $\mathrm{pH}=6.994$ and $25.0^{\circ} \mathrm{C}$. 
This was not the case in the presence of $\beta \mathrm{CD}$, where $F$ increases linearly with the increase of the $\beta \mathrm{CD}$ concentration. In consequence the model for the complex formation (Equations 1 and 2 ) was not fulfilled. This observation contrasts with results previously reported for other indoles ${ }^{12,13,18}$ where the $\mathrm{K}_{\mathrm{A}}$ values for the interaction between the substrate and the $\beta \mathrm{CD}$ were obtained from the non-linear curve fit. This result could be interpreted as a change in the solvent polarity or a complex formation with a very low value of $\mathrm{K}_{\mathrm{A}}$. However the first explanation could be discarded since no changes of $F$ were observed by the addition of $\alpha \mathrm{CD}, \gamma \mathrm{CD}$ or glucose. The values of $\mathrm{K}_{\mathrm{A}}$ with $\mathrm{HPCD}$ for related indoles ${ }^{12,13,18}$ like $\mathrm{M}$, 3-methylindole, indole 3-acetic acid, tryptamine, 5-methoxytryptamine and 5-hydroxyindoleacetic acid were also higher than those with $\beta \mathrm{CD}$, validating the second claim.

In the case of $\mathrm{mCD}$ and $\mathrm{HPCD}$, the data $\left(F / F_{0}\right)$ plotted according to a linearized equation ${ }^{19,20}$ (not shown) also gave the same values of $\mathrm{K}_{\mathrm{A}}$ within the experimental error, confirming the (1:1) relationship between the substrate and the receptor $(\mathrm{CD}) .^{21}$ The values of $\mathrm{K}_{\mathrm{A}}$ determined for 6HM (Table 1) range from $60-120 \mathrm{~mol}^{-1} \mathrm{~L}$ mainly indicating aromatic inclusion as in other aromatic compounds ${ }^{22}$ and related indoles. ${ }^{12,13,18}$ The $\mathrm{K}_{\mathrm{A}}$ with HPCD for $6 \mathrm{HM}$ is almost half of the values determined for indoles substituted on position 5, like M, 5-methoxytryptamine and 5hydroxyindoleacetic acid, indicating a steric effect produced by the 6-substitution higher than that of the 5-substitution on the indole nucleus for the inclusion of the aromatic nucleus inside the $\mathrm{CD}$ cavity. The higher affinity observed with $\mathrm{mCD}$ than with HPCD resembled that previously reported from 2,4,6-trichlorophenol. ${ }^{23}$

The preceding interpretations of the observed changes in guest fluorescence produced by CD were based mainly from the evidence of inclusion complex formation, hydrophobic interactions and literature data, ${ }^{16,19}$ but they provide limited structural information on the geometry and mode of inclusion. Direct evidence in solution can be obtained from NMR studies, which can show some specific interactions between specific parts of the guest and host, and thus direct evidence of particular mode of inclusion. ${ }^{18,24}$ Accordingly, the ${ }^{1} \mathrm{H}$ NMR (Bruker $400 \mathrm{MHz}$ ) experiments in $\mathrm{D}_{2} \mathrm{O}$ for solutions of $\mathbf{C D}$ and $(\mathbf{S}+\mathbf{C D})$ were performed. The chemical shift differences $(\Delta \delta, \mathrm{ppm})$ between the complex and free inner protons (3 and 5) of CD were -0.01. These experiments were performed with the best ratio between the cyclodextrin and the substrate concentration that produce the higher concentration of complex according to the small $\mathrm{K}_{\mathrm{A}}$ values and the substrate solubility. These small changes are proof of inclusion but do not permit the $\mathrm{K}_{\mathrm{A}}$ determination or the complex structure determination. No more insight was provided by H-NMR studies.

\section{Analytical performance of the supramolecular method}

Taking into account the experimental results described above we selected HPCD as the supramolecular medium for the spectrofluorimetric determination of $6 \mathrm{HM}$, since this receptor showed the most noticeable enhancement in the fluorescence of $6 \mathrm{HM}\left(\phi_{6 \mathrm{HMCD}} / \phi_{6 \mathrm{HM}}\right.$, Table 1$)$. All the experiments were performed at $25,0{ }^{\circ} \mathrm{C}$ since no improvement was observed at $15,0^{\circ} \mathrm{C}$ and less favorable results were obtained at $40,0^{\circ} \mathrm{C}$. As already mentioned, $\mathrm{pH} 6.994$ was chosen and no significant influence was found with the buffer concentration or the ionic strength. The 
precision of the method was established analyzing 10 replicate samples of the analyte, the relative error being no higher than $3 \%$.

The calibration graphs obtained by plotting $F$ concentration of $6 \mathrm{HM}$ were linear in the range studied (at least 10 different concentrations) with good correlations (at least 0.998). All plots of the $y$-residuals in regression ${ }^{25}$ obtained from $(y-\hat{y})$ values (which represent the differences between the experimental and fitted $y$-values) versus $\hat{y}$ show a normal distribution with variance independent of $\hat{y}$. The assessment of the fitted regression model was checked by $F$ test of linear model, which evaluates the null hypothesis $\mathrm{H}_{0}: x$ and $y$ are not linearly related on the basis of ANOVA principles. ${ }^{25}$ In all cases, the value of the ratio obtained between mean square regression and mean square for residuals exceeds the critical value of $F$ for the corresponding degree of freedom ( 1 and at least 10) in each case at a 95\% confidence level. Therefore we can conclude that the fitted linear model seems to be statistically valid.

Table 2 shows the analytical parameters, such as calibration sensitivity $(m)$, standard deviation of blank signal $\left(s_{B}\right)$, and limit of detection $\left(L_{D}\right)$ calculated according to IUPAC definition $\left(3.29 s_{B} / m\right)^{26}$ for $6 \mathrm{HM}$ in the concentration interval $0.5-6.0 \mu \mathrm{mol} \mathrm{L}{ }^{-1}$, in the presence and absence of $10 \mathrm{mmol} \mathrm{L}^{-1} \mathrm{HPCD}$ at 6.994 and at $25^{\circ} \mathrm{C}$. The related values for $\beta \mathrm{CD}$ were also determined in order to compare with results for other indoles previously reported. ${ }^{12,13,18}$ In all cases, the limit of quantification $\left(L_{Q}=10 s_{B} / m\right)$ as defined in the literature ${ }^{26}$ can be calculated from the data in Table 2.

Table 2. Analytical parameters for $6 \mathrm{HM}$ by direct spectrofluorimetry in different media ${ }^{\mathrm{a}}$

\begin{tabular}{cccc}
\hline Parameter & \multicolumn{3}{c}{ media } \\
& buffer & $\beta C D$ & HPCD \\
\hline$m\left(10^{5} \mathrm{~mol}^{-1} \mathrm{~L}\right)^{\mathrm{b}}$ & $(3.60 \pm 0.09)$ & $(5.58 \pm 0.06)$ & $(11.5 \pm 0.2)$ \\
$s_{B}\left(10^{-3}\right)^{\mathrm{c}}$ & $(0.45)$ & $(0.74)$ & $(0.99)$ \\
$L_{D}\left(\mathrm{ng} \mathrm{mL}^{-1}\right)^{\mathrm{d}}$ & $(1.02 \pm 0.02)$ & $(1.09 \pm 0.01)$ & $(0.71 \pm 0.02)$ \\
\hline
\end{tabular}

${ }^{\mathrm{a}}$ At $\mathrm{pH}=6.994, \mu=0.124 \mathrm{~mol} \mathrm{~L}^{-1}$ and $25.0{ }^{\circ} \mathrm{C}$. ${ }^{\mathrm{b}}$ Slope of a calibration graph. The errors are those calculated by the fitting program. ${ }^{\mathrm{c}}$ Standard deviation of 25 blanks. ${ }^{\mathrm{d}}$ Error calculated by error propagation.

The best values of $m$ were obtained employing HPCD as hosts with a $L_{D}\left(0.71 \mathrm{ng} \mathrm{mL} \mathrm{m}^{-1}\right)$ mainly due to the increase of the $m$ value with respect to $\beta C D(110 \%)$ and buffer $(219 \%)$. The $L_{D}$ determined in this work, lower than $1 \mathrm{ng} \mathrm{mL}^{-1}$ with HPCD as a nanosensor for 6HM, indicates a very sensitive method compared with others reported for $6 \mathrm{HM}$ or related indoles, like chemiluminescence $\left.(4-25 \mathrm{ng} \mathrm{mL})^{-1}\right)^{9}$ fluorescence with derivatization reaction $\left(2 \mathrm{ng} \mathrm{mL}{ }^{-1}\right){ }^{8}$ HPLC with fluorescence detection (21.8), ${ }^{27}$ micellar electrokinetic chromatography as preconcentration techniques and capillary electrophoresis (CE) system with UV detection (26$630 \mathrm{ng} / \mathrm{mL})^{28}$ or with multivariate optimization in HPLC $(44 \mathrm{ng} / \mathrm{mL})$ and CE $(13 \mathrm{ng} / \mathrm{mL}){ }^{29}$

Although more sensitive methods $(1 \mathrm{pg} / \mathrm{mL})$ have been reported for the precursor of $6 \mathrm{HM}$ 
(M) as RIA in serum, ${ }^{5 a}$ CG-MS in plasma and saliva ${ }^{6 a}$ and LC- tandem MS using stable isotope dilution in human saliva, ${ }^{7}$ these analyses involve costly equipment and solvents, in conjunction with complex pre-treatment processes.

HPCD as a nanosensor for $6 \mathrm{HM}$ offers an improved spectrofluorimetric analytical method with a simple and fast application.

\section{Applications}

Since 6HM concentrations in biological fluids are important markers for various diseases and ageing-related physiological conditions, it is considered necessary to detect these biomolecules in real matrices. However, whenever a compound is traceable in urine, urine sampling is always preferred to blood samples due to its non-invasive nature. Hence, the methods developed were applied for the quantification of these molecules in urine samples.

Following the method described under Experimental Section, apparent recovery experiments were performed in buffer and methanol urine extracts spiked at $n$ concentration levels (at least five different values) between $0.24-10.00 \mu \mathrm{mol} \mathrm{L}^{-1}$ of the analyte for the direct spectrofluorimetric method ( $\mathrm{pH}$ 6.994) with or without HPCD, in triplicate in each case. Due to the complexity of the urine matrix, the method of standard addition (MOSA) was applied.

The average apparent recoveries $\left(R_{A}{ }^{A}\right)$ for the triplicates at $n$ levels of fortification in each condition calculated with $m$ in the absence of matrix reveal minimal positive effects of $117 \%$ and $106 \%$ for the buffer urine extracts without and with HPCD, respectively. In the case of methanol urine extract, a high negative and positive matrix effect was observed for the $R_{A}{ }^{A}$ values in the absence (50\%) and presence of HPCD (200\%). In all cases the calibration parameters determined in the matrix provide satisfactory $R_{A}{ }^{A}$ and a normalization of the proportional error. The latter is indicated from the lower statistical test $t$ calculated by Equation 3 compared to the tabulated $\left(t_{(n-1), \alpha=0,05}\right)$.

$$
t=\left[\left(\% R_{A}{ }^{A}-100\right)(n)^{1 / 2}\right] / s
$$

\section{Conclusions}

Supramolecular complex with HPCD provides an alternative, efficient and direct spectrofluorimetric method for the determination of $6 \mathrm{HM}$. The $L_{D}$ reported here for the direct $\left(0.7 \mathrm{ng} \mathrm{mL}^{-1}\right)$ method is better than, or in the same order as, the spectrophotometric, fluorimetric and HPLC with fluorescence detection methods informed in the literature.

In addition, these $L_{D}$ assess the quantification $\left(L_{Q}\right)$ of $6 \mathrm{HM}$ normal urinary daily excretion in human adults $\left(10 \mu \mathrm{g} /\right.$ day). These values are equivalent to $10 \mathrm{ng} \mathrm{mL}^{-1}$ in the amount of diluted urine extract $(0.2 \mathrm{~mL}$ of urine extract in $10 \mathrm{~mL}$ of final volume $)$ used in the apparent recovery experiments. The present spectrofluorimetric methods in the presence of HPCD as a nanosensor, 
a commercially available macrocyclic receptor, avoid potentially harmful experimental conditions, derivatization reactions, and the use of hazardous solvents by simplifying the experimental requirements.

\section{Experimental Section}

General. UV-vis and spectrofluorimetric determinations were carried out on a Shimadzu UV$2101 \mathrm{PC}$ and a Jasco FP-777 respectively. The pH was measured on an Orion model 720 (resolution 0.001 ; relative accuracy \pm 0.002$)$ at $(25.0 \pm 0.1){ }^{\circ} \mathrm{C}$ using a Ross combination $\mathrm{pH}$ electrode. The $\mathrm{pH}$-meter was calibrated using standard buffers $(\mathrm{pH}=2.932 ; 6.994$ and 9.155) prepared according to the literature. ${ }^{30}$ An ultrasonic bath (Testlab tb02) was used for the dissolution of the reagents. Data analysis was performed with Sigma Plot (Scientific Graph system) version 8.00 (Jandel Scientific) and Info Stat Statistical Package, version beta (Facultad de Ciencias Agropecuarias, Universidad Nacional de Córdoba, Argentina).

\section{Reagents}

The water was obtained using a Millipore apparatus. 6HM (99\% purity, ICN), HPCD (degree of substitution 5.5, Cerestar), $\mathrm{mCD}$ (degree of substitution 3.5) and $\beta \mathrm{CD}$ (Roquette), and glucose (Anedra) were used as received. The buffers were prepared according to literature procedures ${ }^{30}$ and buffer solution at $\mathrm{pH}=6.994\left(0.020 \mathrm{~mol} \mathrm{~L}^{-1}\right.$ monopotassium dihydrogenphosphate, 0.030 mol L-1 disodium hydrogenphosphate, and $0.020 \mathrm{~mol} \mathrm{~L}^{-1}$ sodium chloride) were used as reference solution. The basic $\left(\mathrm{pH}=13.00\right.$ is $\left.0.1 \mathrm{~mol} \mathrm{~L}^{-1} \mathrm{NaOH}\right)$ and acid $\left(\mathrm{pH}=2.00\right.$ is $\left.0.01 \mathrm{~mol} \mathrm{~L}^{-1} \mathrm{HCl}\right)$ solutions were prepared from concentrated solutions of $\mathrm{NaOH}\left(1 \mathrm{~mol} \mathrm{~L}^{-1}\right)$ or $\mathrm{HCl}\left(4 \mathrm{~mol} \mathrm{~L}^{-1}\right)$ respectively. All constituents of the buffers were commercial reagents of analytical grade. Methanol was HPLC grade (Sintorgan).

\section{General procedure}

A concentrated solution of substrate in water $(2 \mathrm{mg} / 10 \mathrm{~mL})$ was stored in the refrigerator $\left(4^{\circ} \mathrm{C}\right)$ for a maximum of one week. The stability of the stock solutions was periodically checked by spectrophotometry before preparing the appropriate dilutions for fluorimetric determinations. Water solutions were prepared by adding the stock solution of substrate to the reference buffer solution prepared as indicated above and diluting to the mark with water. The concentration of the buffer in the final solution was $95 \%$ of the original reference buffer solution. All solutions were covered with aluminium foil. For emission and excitation fluorescence spectra the photomultiplier gain was medium (acidic or neutral media) or high (basic media) with $10 \mathrm{~nm}$ emission and excitation bandwidths. The fluorescence emission spectra were taken with excitation wavelength equal to the wavelength of maximum absorption. All the determinations were made at $(25.0 \pm 0.1){ }^{\circ} \mathrm{C}$, and the temperature of the cell compartment was controlled with a Haake circulator. The solutions were not degassed. A solution of $2.40 \mu \mathrm{mol} \mathrm{L}^{-1}$ of the substrates 
at $\mathrm{pH}=6.994$ was used as reference for the fluorimetric measurements. The ionic strength $(\mu)$ of all solutions was $0.124 \mathrm{~mol} \mathrm{~L}^{-1}$ by adding $\mathrm{NaCl}$ when required.

For the determination of the overall association constant, two solutions of the same substrate concentration (one without receptor and the other with the maximum concentration of the receptor used) were mixed in the proper proportion, in order to vary the receptor concentration and minimize the changes in fluorescence resulting from those changes in the substrate concentration. ${ }^{31}$ The solutions were stabilized half an hour before the measurement, and the overall manipulation of a solution was no longer than eight hours since spectral changes were observed over time.

For the spectrofluorimetric determination, the total area below the fluorescence spectrum $(F)$ (Equation 4$)$ and the fluorescence intensity at a fixed emission wavelength $\left(F_{\lambda}\right)$ (Equation 5 ) were measured:

$$
\begin{gathered}
\boldsymbol{F}=\boldsymbol{B} \sum \varepsilon_{i} \phi_{i}[\boldsymbol{i}] \\
\boldsymbol{F}_{\lambda}=\boldsymbol{B} \sum \varepsilon_{i} \phi_{i} \gamma_{i}[\boldsymbol{i}]
\end{gathered}
$$

where $B$ is a constant which depends on the instrumental set-up, $\varepsilon_{i}$ is the molar absorptivity at the $\lambda^{\mathrm{ex}}, \phi_{i}$ is the fluorescence quantum yield, $\gamma_{i}$ is the fraction of the total emission intensity at a given wavelength and $(i)$ indicates the concentration of each fluorescent species $i$. In all cases the absorbance of the solution was $<0.025$, where Equations (4) and (5) are valid.

\section{Extraction and analysis of biological samples}

Urine samples of a healthy adult collected and stored at $\mathrm{pH}=2.00$ as recommended in the literature, ${ }^{32}$ and extracted as described below, were used for the MOSA in apparent recovery analysis. The drugs and diets that could produce false positive or false negative results were restricted to three or four days prior to and during collection, as reported in the literature. ${ }^{32}$

The efficiency of the analyte extractions from spiked samples of acid urine was evaluated. The conventional method ${ }^{33}$ consisting of one extraction with ether and a re-extraction with aqueous buffer at $\mathrm{pH}=7.00$ showed poor recoveries $(24 \%)$ for $6 \mathrm{HM}$ (neutral substrate). The extraction procedures were tested in order to optimize this process. Thus, the best results were achieved when the acidic urine ether extract was evaporated and taken with methanol. This extraction procedure yielded quantitative recoveries similar to those reported for neutral substrates. ${ }^{12}$ In the apparent recovery analysis, a final volume of $0.200 \mathrm{~mL}$ of the buffer or methanol urine extract (equivalent at $0.100 \mathrm{~mL}$ of the original urine sample) was placed in a $10.00 \mathrm{~mL}$ volumetric flask in the buffer or with the appropriate HPCD concentration in the buffer. At least five different amounts of the respective hydroxyindole compound were added in order to give concentrations between $0.2-10.0 \mu \mathrm{mol} \mathrm{\textrm {L } ^ { - 1 }}$. In all cases, the fluorescence signal of the corresponding blank was $10 \%$ lower than that obtained for the smallest spiked concentration, subtracted from the overall signal. All the determinations were done in triplicate. 


\section{Acknowledgements}

This research was partly supported by Consejo Nacional de Investigaciones Científicas y Técnicas (CONICET), Argentina, Secretaría de Ciencia y Tecnología de la Universidad Nacional de Córdoba (SECyT-UNC) and Agencia Nacional de Promoción Científica y Tecnológica (FONCYT). A. G. B was a grateful recipient of a fellowship from CONICET and FONCYT. We would like to mention the participation of Agustín Luna and Matías Carranza as training undergraduate and postgraduate students, respectively, in performing some determinations of the experimental work.

\section{References}

1. Burtis, C. A.; Ashood, E. R.; Bruns, D. E. In Tietz Textbook of Clinical Chemistry and Molecular Diagnostics, $4^{\text {th }}$ ed., Elsevier Saunders, 2006, Chap. 29, pp 1033-1074.

2. Wilson, J. D.; Foster D. W.; Kronemberg, H. M., Larsen, P. R. In Williams Textbook of Endocrinology, $9^{\text {th }}$ Edn., W. B. Saunders Company, 1998, pp 216-225.

3. Celis, M. E. In Fisiología Humana. Sistema Nervioso y Sistema endócrino; 1st Edn., U.N.C., 1998., pp 103-104.

4. Zimmermann, R. C.; Mc Dougle, C. J.; Schumacher, M.; Olcese, J.; Heninger, G. R.; Price, L. H. Psychoneuroendocrinology 1993, 18, 567.

5. (a) Manz, B.; Seidel, A.; Alexander, H.; Vollrath, L.; Wagner, B.; Zimmerman, G.; Wiedemann, K.; Pollow, K. J. Clin. Chem. Clin. Biochem. 1989, 27, 797. (b) Di, W.; Kadva, A.; Djahanbakhch, O.; Silman, R. Clin. Chem. 1998, 44, 304.

6. (a) Simonin, G.; Bru, L.; Leliévre; E.; Jeanniot, J. P.; Bromet, N.; Walther, B.; BoursierNeyret, C. J. of Pharmaceutical and Biomedical Analysis 1999, 21, 591. (b) NúñezVergara, L. J.; Squella, J. A.; Sturm, J. C.; Baez, H.; Camargo, C. J. Pharmaceutical and Biomedical Analysis 2001, 26, 929.

7. Eriksson, K.; Ostin, A.; Levin, J. J. Chromatography B 2003, 794, 115.

8. Nakamura, H.; Pisano, J. J. Archives of Biochemistry and Biophysics 1976, 172, 98.

9. (a) Lu, J.; Lau, C.; Lee, M. K.; Kai, M. Anaytica Chimica Acta 2002, 455, 193. (b) Chen, G. N.; Huang; F. X.; Wu, X. P.; Zhao, Z. F.; Duan, J. P. Anal. Bioanal. Chem. 2003, 376, 873.

10. Anslyn, E. V. J. Org. Chem. 2007, 72, 687.

11. Pacioni, N. L.; Sueldo Occello, V. N.; Lazzarotto, M.; Veglia, A. V. Anal. Chim. Acta 2008, $624,133$.

12. Galian, R. E.; Bracamonte, A. G.; Veglia, A. V. Anal. Chim. Acta 2005, 540, 393.

13. Galian, R. E.; Veglia, A.V. J. Photochem. Photobiol. A 2007, 187, 356.

14. Pacioni, N. L.; Bracamonte, A. G.; Veglia, A. V. Journal of Photochem. and Photobiol. A: Chemistry 2008, 198, 179-185.

15. Frankewich, R. P.; Thimmaiah, K.N.; Hinze, W. L. Anal. Chem. 1991, 63, 2924. 
16. (a) Dodziuk, H., Ed. In Cyclodextrins and Their Complexes, Wiley-VCH: Weinhein, 2006. (b) Bender, M. L.; Komiyama, M. In Cyclodextrin Chemistry, Edn. Springer-Verlag: Berlin, Heidelberg, 1978.

17. Lide, D. R. In CRC Handbook of Chemistry and Physics, Internet Version 2005, http://www.hbcpnetbase.com ed. CRC Press: Boca Raton, FL, 2005.

18. Bracamonte, A.G.; Veglia, A.V. Talanta 2011, 83, 1006.

19. Connors, K. A. In Binding Constants, Wiley: New York, 1987.

20. Cramer, F.; Saenger, W.; Spatz, H. J. Am. Chem. Soc. 1967, 89, 14.

21. Muñoz de la Peña, A.; Salinas, F.; Durán-Merás, I.; Moreno, M. D. Anal. Lett. 1994, 27, 1893.

22. Connors, K. A. Chem. Rev. 1997, 97, 1325.

23. Hanna, K.; de Brauer, C.; Germain, P. Journal of Hazardous Materials B 2003, 100, 109.

24. (a) Wagner, B.D. in Cyclodextrin Materials Photochemistry, Photophysics and Photobiology; Douhal, A. Ed., Elsevier, UK, 2006, p 28. (b) Scheneider, H-J.; Yatsimirsky, A. K.; "Principles and Methods in Supramolecular Chemistry", John Wiley \& Sons Ltd, England, 2000, p 231. (c) Cohen, Y.; Avram, L.; Evan-Salem, T.; Frish, L. in "Analytical Methods in Supramolecular Chemistry”, Schalley, C. A. Ed., Wiley-VCH, Weinheim, 2007, p 163.

25. Miller, J. N. Analyst 1991, 116, 3.

26. Inczédy, J.; Lengyel, T.; Ure, A.; Gelencsér, A.; Hulanicki, A. (eds) in Compendium of analytical nomenclature (definitive rules 1997), third ed, Blackwell Science England, 1998.

27. Minami, M.; Takahashi, H.; Inagaki, H.; Yamano, Y.; Onoue, S.; Matsumoto, S.; Sasaki, T.; Sakai, K. Journal of Chromatography B 2009, 877, 814.

28. Musijowski, J.; Pobozy, E.; Trojanowicz, M. Journal of Chromatography A 2006, 1104, 337.

29. Hevia, D.; Botas, C.; Sainz, R.M.; Quiros, I.; Blanco, D.; Tan, D.X.; Gomez-Cordoves, C.; Mayo, J.C. Journal of Chromatography A 2010,1217,1368.

30. Strauts, C. R. N.; Gilfillan, J. H.; Wilson, H. N. in Analytical Chemistry The working tools, ed. Oxford University Press, London, 1958, Vol. I, 228.

31. Patonay, G.; Rolie, M. E.; Warner, I. M. Anal. Chem. 1985, 57, 569.

32. Tietz, N.W. in Fundamentals of Clinical Chemistry, $3^{\text {rd }}$ ed., W. B. Saunders Company, Philadelphia, 1987, p 607.

33. Kaplan, L. A.; Pesce, A. J. in Química Clínica, Editorial Médica Panamericana, Buenos Aires, Argentina, 1990. 